\title{
Introduction to the Symposium on the Extended Effects of the Affordable Care Act
}

\author{
Reagan Baughman ${ }^{1} \cdot$ Dhaval Dave $^{2} \cdot$ Angela Dills $^{3}$
}

Published online: 10 October 2018

(C) EEA 2018

The health insurance system in the USA historically was fragmented and incomplete. Individuals could be covered by employer-sponsored plans, other privately purchased plans, or the government-or left without insurance coverage entirely. In 2009, 16.7\% of Americans were uninsured, an increase from 15.3\% in 2007 (U.S. Census Bureau 2011). The Patient Protection and Affordable Care Act of 2010 (ACA) contained a set of reforms to health insurance markets that have the potential to give almost all Americans access to affordable coverage. Since the start of the twentieth century, there have been a number of attempts at reforms that would give more Americans access to health insurance; these include the creation of Medicaid and Medicare in 1965, but also failed reform efforts between 1934 and 1939 as part of the New Deal, between 1945 and 1950 under President Truman, between 1970 and 1974 under President Nixon, and between 1992 and 1994 under President Clinton. In this sense, the ACA is a truly historic piece of legislation.

The ACA works within the US system of multiple sources of health insurance, with the goal of increasing coverage through both public and private sources. The first provision of the law to take effect, in 2010, required employer-sponsored insurance (ESI) plans with dependent coverage to continue covering these dependents until they reach 26 years of age. The two largest reforms were implemented in 2014.

\footnotetext{
Reagan Baughman

Reagan.Baughman@unh.edu

Dhaval Dave

Ddave@bentley.edu

Angela Dills

Akdills@email.wcu.edu

1 University of New Hampshire, Durham, USA

2 NBER, IZA and Bentley University, Waltham, USA

3 West Carolina University, Cullowhee, USA
} 
One allows states to expand their Medicaid programs to non-elderly adults with incomes below $138 \%$ of the federal poverty line. ${ }^{1}$ The second set of reforms focused on the private market for direct purchases of individual and family plans. The law created Marketplaces that sell policies at four standardized levels of premium and cost-sharing, as well as two types of subsidies to improve the affordability of these plans. It also imposed regulations designed to ensure that all applicants had access to complete and affordable coverage. These regulations included restricting premiums to vary only by age and smoking status and prohibiting plans from excluding treatment for preexisting conditions. The final set of major reforms designed to increase coverage are a mandate that all individuals have health insurance or face a tax penalty $^{2}$ and a mandate that all large employers offer coverage to their employees.

There is strong consensus in the literature, based on multiple national datasets, that the Affordable Care Act significantly expanded coverage and reduced the rate of uninsured non-elderly adults. One of the earliest provisions of the ACA to go into effect, the dependent coverage mandate, targeted the historically low coverage rates among young adults. Just under 30\% of adults aged 19-25 lacked health insurance in 2010; that number dropped to $22.6 \%$ by 2013 (U.S. Census Bureau 2011, 2014). More sophisticated analyses, including the paper by $\mathrm{Xu}$ and Yörük in this issue, have confirmed what the raw trends suggest. Many young adults gained coverage under the dependent coverage mandate; the fraction of young adults who were uninsured declined significantly, by between 5 and 6 percentage points, an increase in dependent coverage of 6-10 percentage points. This was partially offset by a decline in own or spousal coverage (Colman and Dave 2018; Antwi et al. 2013; Cantor et al. 2012).

The ACA has made significant gains in achieving its primary goals of expanding health insurance and reversing the steadily increasing trend in uninsurance. Among the non-elderly, the uninsured rate fell from $18.4 \%$ in 2010 to a historic low of $10.1 \%$ in 2016, as almost 26 million Americans newly gained coverage (U.S. Census Bureau 2011, 2017). Most of this drop is attributed to the ACA, with about $60 \%$ of the ACA coverage gains produced by Medicaid and about $40 \%$ produced by the exchange premium subsidies (Frean et al. 2017). Coverage gains under the ACA have been broadly realized, with the uninsured rate falling for all subgroups of adults under the age of 65 across gender, race and ethnicity, and educational attainment (Garrett and Gangopadhyaya 2016). The uninsured rate has declined in every state, even among states that did not expand Medicaid, partly due to the ACA bringing out of the "woodwork" populations that were previously eligible for Medicaid and raising their take-up rates of Medicaid (Frean et al. 2017; Garrett and Gangopadhyaya 2016). Additionally, the ACA allowed many non-elderly adults without ESI to find alternative sources of coverage at lower cost that were no longer directly tied to their

\footnotetext{
1 The original law mandated that all states expand their programs. However, in the National Federation of Independent Business v. Sebelius (2012) the Supreme Court ruled that a mandatory expansion was unconstitutional. To date, 33 states have implemented expanded programs and another two have voted to expand but not yet implemented.

2 The Tax Cut and Jobs Act of 2017 effectively repealed the individual mandate by removing these tax penalties. The effect of this law change on coverage remains to be seen.
} 
employment under the ACA, either by becoming newly eligible for Medicaid in the expansion states or by obtaining coverage in the Marketplaces.

Significant expansions in health insurance coverage across the country are likely to have changed important outcomes ranging from utilization of medical care to health status to labor supply. The ACA increased both inpatient and outpatient care utilization, as well as the rate of diagnosis of several chronic diseases (Wherry and Miller 2016). It therefore has the potential to affect health outcomes and health behaviors that may be either complements or substitutes for preventive care. Health care is extremely expensive in the United States; per capita spending in 2016 was $\$ 10,348$. To the newly insured individual, the financial benefits of insurance may be substantial. Finally, because of the historically strong link between employment and health insurance coverage, anything that creates affordable options for coverage through channels other than employers likely affects a variety of employment decisions. In this issue, our authors explore these effects and others.

Courtemanche and his coauthors consider how the ACA has impacted investments in health capital, capitalizing on multiple years of pre- and post-policy data from the Behavioral Risk Factor Surveillance System. Newly gaining coverage is predicted to increase preventive health care, by reducing the cost to the consumer, though this reduction in out-of-pocket costs of medically treating disease could also lead to ex ante moral hazard and a decline in behaviors that improve health. Newly gaining coverage resembles an in-kind transfer and amounts to a sizeable income effect, which may have positive or negative effects on health behaviors. Courtemanche and coauthors find that the ACA increased various forms of preventive care utilization, including well-patient checkups, mammograms, and HIV testing, reflecting the reduction in out-of-pocket costs. They also find some evidence that the ACA increased risky drinking, consistent with an ex ante moral hazard effect. One innovation in their study is that they attempt to disentangle the effects of the ACA-driven Medicaid expansion versus the other reforms to the non-group market. In doing so, they find that, interestingly, the effects on preventive care and health behaviors are driven less by the Medicaid expansion and more by the other reforms to the private non-group market and subsidized health insurance exchanges. The results point to the ACA having potential long-term effects on health, through its effects on preventive care and behaviors, and underscore the potential for ex ante moral hazard that may partly undermine some of the positive effects of gaining coverage.

Levy, Buchmueller, and Nikpay highlight the in-kind transfer and potential income effect realized from newly gaining Medicaid coverage under the ACA and examine how the Medicaid expansions affected health and non-health spending by low-income households. They find the expansions significantly reduced average healthcare spending by low-income households, consistent with health insurance access lowering out-of-pocket medical spending. The reduction, however, was relatively small compared to the household's total budget and hence did not lead to any discernible change in non-health spending. This suggests that any consumption increases resulting from the Medicaid expansion may not be equivalent to those from an equal-valued cash transfer for low-income households, possibly because low-income households were spending little out-of-pocket on medical care to begin with. This, however, does not necessarily mean that the expansions did not impact 
household well-being. Medicaid coverage raised total household consumption (health plus non-health) and improved the financial position of these households and the hospitals serving them, even if there are no significant changes in these households' consumption of other goods.

Other papers in this symposium consider broader spillover effects of the ACA on worker mobility. The dominance of ESI as a form of coverage access in the United States may constrain worker mobility, with workers being reluctant to leave their current employment for one where they may be more productive or which may yield greater utility out of fear of losing their insurance. This "job-lock" can assume many forms, restricting mobility from one full-time job to another full-time job, to selfemployment and entrepreneurial activities, to a part-time job, to non-work-related activities, and to retirement. The remaining papers in the symposium assess whether different provisions of the ACA eased these various forms of job-lock.

The study by $\mathrm{Xu}$ and Yörük is the first to apply a regression discontinuity design in examining the effects of the ACA's dependent care provisions on coverage and labor market outcomes, exploiting the sharp discontinuity in dependent coverage eligibility at the age of 26 . They find robust evidence that aging out of the mandate reduced dependent coverage among young adults; the net decrease in overall coverage, however, is lower as some of them shifted from non-employment to employment and took up ESI or other sources of private coverage. Thus, access to coverage that is not directly tied to employment (until the age of 26) is found to reduce employment at the extensive margin, but there are no significant effects on job mobility or on labor supply at the intensive margin. The implication is that young adults, when they gain coverage as dependents while under the age of 26, are spending more time on non-work activities. Consistent with this interpretation, some prior work (Colman and Dave 2018) has suggested that these adults tend to spend more time on education and in searching for jobs (possibly more suitable jobs) which presumably make them better off in the long run. Interestingly, Xu and Yörük also find that the employment effects are larger among males than females, which has implications for the matching of skills and jobs across genders. If this matching is inefficient due to "job-lock," then the availability of low-cost coverage outside of work would lead to a shift in employment. If, on the other hand, the job-lock is minimal and the matching is optimal for the worker and the firm, there may be no such shift in employment.

Chatterji, Liu, and Yörük explore a potentially unintended consequence of the ACA's dependent coverage mandate and assess whether it impacted a very specific margin between work and non-work that has not been previously studied, namely military participation. Given the high uninsured rates among young adults, military health insurance may constitute an important benefit for some young adults who are on the margin of enlisting. If these young adults now gain access to insurance coverage outside of their work or outside their participation in the military, as they do under the dependent coverage mandate of the ACA, then this may also impact their decision to enlist. Chatterji, Liu, and Yörük find evidence that the mandate led to a significant reduction in serving on active duty, particularly for men. They find that some of these men may have switched from active duty (which provides no-cost and more comprehensive health insurance coverage) to the National Guard/ 
Reserves (which provide low-cost, though not free, coverage for some participants) once they are able to access coverage under their parents' plans. The paper provides a broad test of the importance of health insurance benefits in young males' decisions to enlist in and remain on active duty in the US military.

In contrast to the papers by Chatterji et al. and Xu and Yörük, the final two papers by Aslim and by Bailey and Dave in this symposium shift the lens to older adults and assess the impact of the ACA-driven Medicaid expansions on labor market margins that are relevant for this population. Aslim studies retirement behavior among low-educated older adults between the ages of 55-64 who are most likely to gain coverage under Medicaid; he finds that the expansions led to a significant increase in Medicaid enrollment for both men and women, though they increased the likelihood of early retirement only for males. This interesting gender differential points to potential household dynamics, wherein women's decision to retire may depend not only on their own insurance coverage but also on their spouse's or partner's and in general on men's labor market responses and insurance access. Early retirement also has implications for physical and mental health, given the large literature that has shown that retirement causally impacts subsequent health, as well as implications for both Medicaid and Medicare spending as these individuals age into eligibility.

Bailey and Dave provide one of the first studies of whether the ACA eased "entrepreneurship lock" among older adults by providing them an alternate source of lowcost coverage through Medicaid. The focus on older adults is also apt for assessing the margin between wage employment and self-employment given the significantly high prevalence of self-employment among adults ages 60-69 (16\%) compared with younger adults $(10 \%)$. Self-employment further provides an intermediate transition from wage employment for many older workers prior to exiting the labor market completely. Bailey and Dave exploit Medicare's age-related eligibility threshold as a natural experiment, since older adults who are eligible for Medicare by virtue of being over 65 years of age should not be affected by the ACA's market reforms and comprise a plausible control group. They find robust evidence that the expansions led to an economically and statistically significant increase in self-employment among Medicare-ineligible older adults. One implication of these results is that losing health insurance coverage is a barrier to self-employment and entrepreneurship for older adults. Furthermore, given that work in general can be health-promoting, the findings by Bailey and Dave also have implications for longer-term effects on health as older workers transition into retirement.

This historic piece of legislation affected many aspects of the health insurance markets: broadening Medicaid coverage, raising the age of eligibility for dependent care coverage, and creating Marketplaces for private individual and family health insurance plans. The ACA loosened the link between employment and health insurance coverage and significantly expanded health insurance coverage in the United States. This symposium provides an overview of the wide-ranging effects of these reforms. We observe increased preventative care usage, some decreases in healthimproving behaviors, and declines in job-lock as individuals shift away from work, including military participation, and toward entrepreneurship and retirement. Not even a decade into this broad reform, we are better understanding its effects; these papers and their authors contribute greatly to this knowledge. 
Acknowledgements The organizers of this Symposium on the Extended Effects of the Affordable Care Act are grateful to Cynthia Bansak, Diego Nocetti, and Allan Zebedee for their invaluable support and efforts in putting this issue together. We would also like to thank the authors and contributors to this Symposium and the peer reviewers for enriching our understanding of the effects of the ACA. Lastly, we would like to thank Alexandre Olbrecht for his assistance in organizing the Symposium sessions at the 2018 Annual Meeting of the Eastern Economic Association.

\section{References}

Antwi, Y.A., A.S. Moriya, and K. Simon. 2013. Effects of Federal Policy to Insure Young Adults: Evidence from the 2010 Affordable Care Act's Dependent-Coverage Mandate. American Economic Journal: Economic Policy 5 (4): 1-28.

Cantor, J.C., A.C. Monheit, D. DeLia, and K. Lloyd. 2012. The Role of Federal and State Dependent Coverage Eligibility Policies on the Health Insurance Status of Young Adults (No. w18254). Waltham: National Bureau of Economic Research.

Colman, G., and D. Dave. 2018. It's About Time: Effects of the AFFORDABLE Care Act Dependent Coverage Mandate on Time Use. Contemporary Economic Policy 36 (1): 44-58.

Frean, M., J. Gruber, and B.D. Sommers. 2017. Premium Subsidies, the Mandate, and Medicaid Expansion: Coverage Effects of the Affordable Care Act. Journal of Health Economics 53: 72-86.

Garrett, B., and A. Gangopadhyaya. 2016. Who Gained Health Insurance Coverage Under the ACA; and Where Do They Live? Washington: Urban Institute. http://www.urban.org/sites/default/files/publi cation/86761/2001041-who-gained-health-insurancecoverage-under-the-aca-and-where-do-theylive.pdf.

U.S. Census Bureau. 2011. Income, Poverty and Health Insurance Coverage in the United States: 2010, P60-P238.

U.S. Census Bureau. 2014. Health Insurance Coverage in the United States: 2014, P60-P250.

U.S. Census Bureau. 2017. Health Insurance Coverage in the United States: 2016, P60-P260.

Wherry, L.R., and S. Miller. 2016. Early Coverage, Access, Utilization, and Health Effects Associated with the Affordable Care Act Medicaid Expansions: A Quasi-Experimental Study. Annals of Internal Medicine 164 (12): 795-803. 